\title{
A contribuição da curadoria digital em repositórios digitais
}

\author{
Fernanda Alves Sanchez \\ Arquivista e Mestranda em Ciência da Informação na Faculdade de Filosofia e Ciências, \\ UNESP/Marília. \\ E-mail: e-mail: feersanchez@gmail.com \\ Silvana Aparecida Borsetti Gregório Vidotti \\ Professora Dr. a do departamento de Ciência da Informação da UNESP/Marília \\ E-mail: svidotti@gmail.com \\ Fernando Luiz Vechiato \\ Professor Dr. do departamento de Ciência da Informação da Universidade Federal do Rio Grande do \\ Norte (UFRN) \\ E-mail: vechiato2004@yahoo.com.br
}

\begin{abstract}
RESUMO:
Instituições de ensino e pesquisa, por meio das Tecnologias de Informação e Comunicação (TIC), fazem uso de ambientes informacionais digitais - denominados Repositórios Digitais - devido à necessidade de disseminar e, acima de tudo preservar suas produções. Dada a preocupação com o valor que os dados digitais e objetos digitais de pesquisa realizadas por essas instituições necessitam, cria-se o conceito de Curadoria Digital que, segundo a Digital Curation Center (DCC), trata-se de manutenção, preservação e agregação de valores aos dados garantindo uso e reuso dos dados no presente e no futuro. Nessa pesquisa temos como objetivo contextualizar quais as contribuições da Curadoria Digital em Repositórios Digitais, a partir do modelo de ciclo de vida. A metodologia de pesquisa caracteriza-se como exploratória e bibliográfica, possuindo uma abordagem qualitativa, por meio do método de análise de conteúdo. Podemos verificar que a aplicação de atributos presentes no modelo do ciclo de vida da Curadoria Digital usado para essa pesquisa transforma esses ambientes informacionais digitais em espaços colaborativos de qualidade em relação a padrões e normas, organização, recuperação, acesso, disseminação e preservação da informação.
\end{abstract}

Palavras-chave: Curadoria digital. Preservação digital. Repositórios digitais.

\section{ABSTRACT:}

Educational and research institutions, together with the Information and Communication Technologies (ICT), make use of digital information environments called Digital Repositories - due to the need to disseminate and, above all, preserve their productions. Given the concern about the value that data and digital objects of research carried out by these institutions need, the concept of Curated Digital is created which , according to the Digital Curation Centre (DCC), it is maintaining , preserving and adding value data, ensuring use and reuse of the same in the present and in the future. In this research we will analyze what the Digital Curation Lifecycle contributes in Digital Repositories, and scoring the technologies used in each of the stages of this cycle. The research methodology is characterized as exploratory and literatur, having a qualitative approach using content analysis method. We can see that the application of the attributes present in the model of Curated Digital life cycle used for this research transforms these digital information environments in 
collaborative spaces of quality in relation to standards and norms, organization, retrieval, access, dissemination and preservation of information.

Keywords: Digital curation. Digital preservation. Digital repositories.

\section{INTRODUÇÃO}

A evolução das Tecnologias de Informação e Comunicação (TIC) a partir da década de 90 contribuiu com o surgimento da Internet e do ambiente da Word Wide Web $(W W W)$. A quantidade de dados gerados na Internet cresce consideravelmente, sobretudo por conta da participação do usuário nesse espaço digital. $\mathrm{O}$ ambiente Web, considerado ainda hoje como a Web colaborativa ou Web 2.0, permite que os usuários além de consumidores da informação possam contribuir para geração de conteúdo.

Atualmente a informação passa por um momento forte de disseminação e interação graças aos novos suportes tecnológicos, resta saber se essa informação é confiável, de qualidade e acessível. Para isso é importante que os ambientes digitais sejam estruturados permitindo acesso de todo e qualquer tipo de usuário de forma eficaz e eficiente, assim, estudos na área da Ciência da Informação se fazem necessários, elaborando e adequando os ambientes informacionais digitais por meio de diversas áreas do conhecimento como: Ciência da Computação, Linguística, entre outras.

A busca por sistemas informacionais que disponibilizem e preservem os dados gerados por organizações e instituições ensino e pesquisa aumentam gradualmente, destacando-se o uso de Repositórios Digitais (RD), ambientes desenvolvidos por meio de softwares livres, que podem caracterizar-se como: Repositórios Institucionais (RI), Repositórios Temáticos (RT) e Repositório de Dados (RD).

A partir dessa iniciativa os repositórios caracterizam-se pelo Movimento de Acesso Aberto, ou seja, disponibilização de dados gerados pelas instituições de maneira aberta, sem custos, proporcionando transparência das informações, além de disseminação das mesmas, fato importante para divulgação das pesquisas realizadas, podendo assim, revelar trabalhos de suma importância à sociedade. 
Os RDs devem ser implementados de forma estruturada, estabelecendo normas e padrões que facilitem sua utilização. Surge então à contribuição da Curadoria Digital com o intuito de oferecer seus serviços para que o gerenciamento dos dados científicos ou dos objetos digitais inseridos nesses ambientes seja efetivo, além de acompanhar todo o ciclo de vida desses dados, ou seja, todas as etapas da inserção de dados ou objetos digitais nesse ambiente, desde sua criação, até o momento de descarte - denominaremos como objetos digitais os documentos inseridos de diversas tipologias documentais.

Como objetivo geral dessa pesquisa, buscamos analisar quais as contribuições Curadoria Digital a partir de uma breve análise no Curation Lifecycle Model (CLM) desenvolvido pela Digital Curation Centre (DCC) e o que elas podem contribuir para o funcionamento dos Repositórios Digitais, objeto de estudo dessa pesquisa. Além disso, pontuamos algumas tecnologias, linguagens e softwares que podem ser utilizados para atender desenvolver etapas relacionadas ao modelo de curadoria digital.

Dada a problemática de padronização na inserção de dados, objetos digitais e estruturação dos sistemas informacionais, dificultando o acesso de qualidade às informações, tanto no processo de navegação, quanto na Encontrabilidade da Informação para uso e reuso de informação, buscamos propor soluções para que a preservação de conteúdos seja satisfatória a partir dos conceitos de Curadoria Digital e contribuições em Repositórios Digitais, por meio de tecnologias e linguagens de representação.

Justifica-se a importância dessa pesquisa por contribuir com ambientes informacionais digitais de caráter colaborativo como os Repositórios Digitais que buscam organizar, estruturar, permitir acesso, disseminar e preservar todos os dados gerados por meio de pesquisas realizadas em sua maioria por Instituições de Ensino e Pesquisa. É importante destacar que a partir da elaboração de um sistema informacional adequado, o uso e reuso das informações inseridas no mesmo são mais satisfatórias aos indivíduos que fazem uso desse espaço, garantindo qualidade no compartilhamento de conhecimento por meio da comunicação científica, além de contribuir com a preservação dessas informações, impulsionando novas pesquisas e evitando pesquisas duplicadas.

Ainda podemos destacar a relevância dessa pesquisa em relação ao conceito de Curadoria Digital e ao modelo de Ciclo de Vida realizado pela Digital 
Curation Center (DCC), por conta da necessidade de aprofundamento no tema por ser relativamente novo na área da Ciência da Informação, contribuindo, assim, para o desenvolvimento desse conceito em ambientes informacionais como os Repositórios.

\section{CURADORIA DIGITAL}

Abordamos um termo relativamente novo dentro da área da Ciência da Informação nesse texto, a Curadoria Digital, especificamente tratada nesse trabalho no contexto do Ciclo de Vida de dados e objetos digitais.

Terra (2012) contextualiza a sociedade da informação em que vivemos e a importância do profissional responsável por essa área, sendo assim:

[...] a curadoria da informação é mais um desafio trazido pela sociedade da informação, pela fartura de dados e pelo excesso de conteúdo disponível na rede. [...] Vivemos em uma "dadosfera", uma vez que a disposição de dados ao nosso redor nunca ocorreu antes na história. E como essa avalanche informacional não diz respeito necessariamente à qualidade, a situação justifica a existência do curador. (TERRA, 2012, p.61)

Com o volume de dados gerados no ambiente da Word Wide Web (WWW) crescendo exponencialmente, sejam eles gerados digitalmente ou migrados para os formatos digitais surgem questionamentos sobre garantir a guarda, organização, gerenciamento, tratamento, representação, recuperação e preservação dessas informações com qualidade.

Além disso, por conta da constante evolução das Tecnologias de Informação, geram-se preocupações ainda maiores com as possibilidades de obsolescência dos hardwares e softwares utilizados para criação de sistemas informacionais, além dos formatos dos objetos digitais gerados e dos dados científicos.

Nesse contexto, a Curadoria Digital que "[...] evoluiu das noções de preservação digital e da necessidade da informação ser divulgada em meio aberto, principalmente a informação científica produzida em rede e de forma distribuída. (SANTOS, 2014, p. 29)", segundo a DCC a curadoria visa determinar a qualidade do ciclo de vida dos dados, proporcionando assim acesso tanto no presente quanto no futuro e determinando seu tempo de vida útil. 
O termo curadoria vem do ato de curar que significa cuidar e zelar. O curador é visto como alguém que filtra, organiza e que protege. A partir disso podemos montar o perfil e caráter de um curador que pode vir a ser um curador digital, como alguém que cuida e oferece tratamento para uma série de dados digitais.

O curador, de acordo com Santos (2014), tem como papel a implantação de padrões para conjunto de dados; o planejamento prévio ao estabelecimento dos objetos digitais; adição de valor; descrição e representação do conteúdo por metadados ou anotações e boas práticas em gestão de dados digitais.

Abbott (2008) acentua que fazem parte da Curadoria Digital todas as atividades envolvidas no gerenciamento de dados, planejamento e criação, melhores práticas em matéria de digitalização da documentação asseguram a sua disponibilidade e adequação para descoberta e reutilização no futuro.

O discernimento do que serve ou não no mundo digital é um dos papeis da curadoria. A curadoria digital é um filtro em meio ao crescimento de informações digitais e pode ser uma alternativa para organizações.

A curadoria digital deve acontecer dentro da instituição, em conjunto com uma boa gestão documental e políticas de funcionamento dos Repositórios Digitais, contribuindo com as tecnologias que serão utilizadas. A questão do acesso à informação de maneira fácil e em qualquer período de tempo é uma das grandes preocupações da curadoria digital.

Santos (2014, p. 30) destaca:

Curadoria tem uma abordagem "vida inteira" para materiais digitais para abordar a seleção, manutenção, coleta e o arquivamento de ativos digitais, além de sua preservação. É um conceito útil para descrever a visão evolutiva de todo o ciclo de vida da preservação digital, mas concentra-se em atividade que alicerçam a construção e gestão de coleções de ativos digitais.

Dentre os ambientes informacionais digitais em que a curadoria digital pode se aplicar, os mais utilizados serão instituições de ensino e pesquisa que buscam preservar os dados científicos das pesquisas realizadas, em diversos formatos documentais. Essas instituições na busca de armazenar, organizar, recuperar e principalmente preservar seus dados, criam ambientes informacionais digitais que atendam tais necessidades, como por exemplo, bibliotecas digitais ou repositórios digitais que atendem as políticas do Open Acess. 
O Digital Curation Center (DCC), conforme sua página na Web (http://www.dcc.ac.uk/) é um centro que tem especialidade em curadoria digital. Ele tem como base a construção de capacidade e habilidades para gestão de dados de pesquisa. A DCC elaborou o Curation Lifecycle Model (CLM) que pode ser utilizado para melhorar processos de criação e gestão dados, além de uma curadoria em longo prazo; esse modelo, no dia 01 de Março de 2004, é apropriado para uso em repositórios digitais. Um dos grandes motivos de sua criação foi à recomendação do Continuing Access and Digital Preservation Strategy for the Joint Information Systems Committee (JISC), onde explicou a necessidade de um centro nacional para resolver desafios em curadoria digital que não poderiam ser resolvidos por qualquer instituição ou disciplina. Esse centro fornece aconselhamento e ajuda prática às organizações de investigação que desejam armazenar, gerenciar, proteger e compartilhar dados de pesquisa digitais.

Figura 1 - Curation Lifecycle Mode/(CLM)

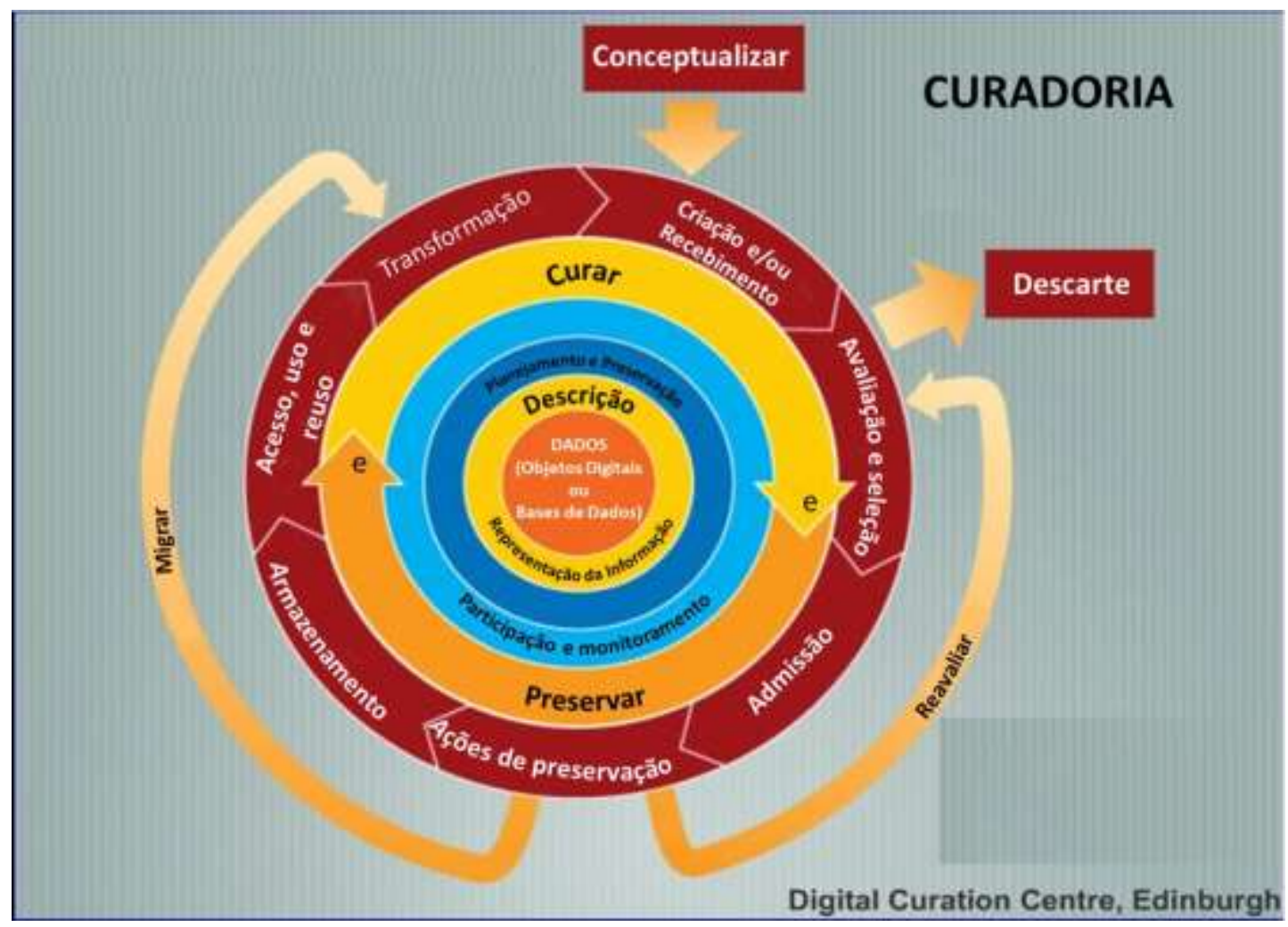

Fonte: Digital Curation Center(DCC) traduzido por Vidotti (2016). Disponível em: http://www.dcc.ac.uk/resources/curation-lifecycle-model

O centro do CLM identifica e planeja as atividades da Curadoria Digital a partir da concepção dos dados ou recebimentos de dados, como no caso dos Repositórios Digitais, ambiente de estudo dessa pesquisa. O modelo da DCC tem 
três elementos centrais que podem direcionar o processo da Curadoria, em busca de contextualizá-las, segue a citação de Sales e Sayão (2012, p. 126):

Os elementos chaves do modelo são: dados, objetos digitais e bases de dados. No centro do ciclo de vida da curadoria está o dado digital, que é qualquer informação codificada em formato binário. A ideia de dado inclui: os objetos digitais simples, que são aqueles compostos por um único arquivo, identificador e metadados; e os objetos digitais complexos, que por sua vez são formados pela combinação de outros objetos digitais, formando uma unidade discreta, como é, por exemplo, uma página web. As bases de dados são definidas como coleções estruturadas de registros ou de dados armazenados em sistemas de computadores.

Dentro do contexto de que os RDs estão ligados as instituições de pesquisa e ensino o conceito de Curadoria Digital pode contribuir com um funcionamento adequado, visto que "[...] é a gestão ativa dos dados ao longo do ciclo de vida de interesse acadêmico e científico; é a chave para a reprodutividade e reutilização" (ATKINSON et al, 2005, p.3).

No contexto da Curadoria Digital com os dados digitais Sayão e Sales, destaca que: (2012, p. 185):

A curadoria digital, em resumo, assegura a sustentabilidade dos dados para o futuro, não deixando, entretanto, de conferir valor imediato a eles para os seus criadores e para os seus usuários. Os recursos estratégicos, metodológicos e as tecnologias envolvidas nas práticas da curadoria digital facilitam o acesso persistente a dados digitais confiáveis por meio da melhoria da qualidade desses dados, do seu contexto de pesquisa e da checagem de autenticidade.

Sendo assim, podemos concluir que o conceito da Curadoria Digital consiste em um termo:

guarda-chuva que está em franco desenvolvimento, que abarca definições correlatas voltadas à seleção, enriquecimento, tratamento e preservação da informação para o acesso e uso futuro, seja ela de natureza científica, administrativa ou pessoal (SANTOS, 2014, p.130).

Tal definição deixa clara a abrangência do termo em relação a sua função, podendo contribuir em diversos processos presentes, dentro de uma boa gestão informacional de um Repositório Digital em relação a dados científicos ou objetos digitais.

\subsection{REPOSITÓRIOS DIGITAIS}


Repositórios Digitais (RD) são considerados sistemas de informação utilizados em sua grande maioria em ambientes acadêmicos e instituições de pesquisa que tem como objetivo reunir, organizar, dar acesso, disseminar e preservar produções científicas.

A disseminação da informação se torna a principal característica dos RDs por conta da visibilidade das produções realizadas nas instituições, acontecendo graças à "estrutura de informação que sugere melhor descrição dos recursos do que a própria Web e indica uma melhor recuperação da informação nestes ambientes" (SEGUNDO SANTARÉM, 2010, p.8).

Santarém (2010) ainda apresenta como uma das vantagens a facilidade de publicação e armazenamento de documentos, que podem fornecer serviços de informação de forma estruturada, ou seja, contribuindo para com a organização das informações da instituição produtora.

Em relação ao armazenamento de informação, os repositórios permitem a inserção de diferentes tipologias e formatos documentais, como por exemplo: artigos científicos, teses e dissertações, relatórios de pesquisa, registros administrativos, livros, notícias de jornais, páginas da Web - em formatos como: DOC ou PDF, imagens (JPG, GIF, PNG, BMP, TIFF), áudio e vídeos (RMVB, MPEG, AVI), entre outros. Entretanto, os formatos encontrados de objetos digitais em repositórios, em sua maioria, são em formato PDF, por este ter se tornado um padrão universal.

Os RDs possibilitam o uso de autoarquivamento de objetos digitais, proporcionando ao usuário liberdade para disseminar as produções geradas pelas instituições de ensino e pesquisa, colaborando assim com a comunicação das ciências, nas diversas áreas do conhecimento. No entanto, trata-se de um processo "[...] pouco mais complexo e exige dedicação do usuário, que devera descrever a informação de maneira coesa ao autoarquivar seu objeto digital" (SEGUNDO SANTARÉM, 2010, p.170).

O autoarquivamento não é uma "responsabilidade" das políticas de informação ela deve ser abordada juntamente com as suas diretrizes. A equipe gestora desse ambiente deve determinar padrões e realizar revisões antes dos objetos digitais serem postados, garantindo sua representação de qualidade para acesso e recuperações efetivas. O processo de autoarquivamento deve se tornar uma cultura dentro da comunidade, mostrando as vantagens desse sistema para a comunicação científica. 
Repositórios Digitais tem como uma de suas características principais atender a iniciativa da Open Acess ou, como conhecida no Brasil - Movimento de Acesso Aberto, que teve inicio em uma reunião realizada em Budapeste pelo Open Society Institute (OSI), em dezembro de 2001, onde surgiu a iniciativa do Budapest Open Access Initiative (BOAl) (http://Www.budapestopenaccessinitiative.org/).

O Movimento de Acesso Aberto tem como objetivo incentivar a promoção da literatura científica com o intuito de disponibilizar as produções científicas de modo aberto, ou seja, gratuitamente e sem restrições de acesso.

Segundo o documento da BUDAPEST OPEN ACCESS INITIATIVE (2001):

\begin{abstract}
O acesso aberto é um bem publico que possibilita a distribuição eletrônica das redes de literatura periódica e revisada por pares completamente gratuitas sem restrições de acesso por toda a comunidade cientifica. Retirar as barreiras de acesso a essa literatura acelerará a investigação, enriquecerá a educação, compartilhará o aprendizado dos ricos com os pobres e dos pobres com os ricos. Essa literatura se fará tão útil quanto possível e estabelecerá as bases para unir a humanidade para a busca do conhecimento.
\end{abstract}

Dentro do contexto do Open Acess, surgiu à iniciativa Horizonte $2020^{1}$ - O Programa-Quadro de Investigação e Inovação da União Europeia. Trata-se do maior programa de investigação aberto a todos que busca financiar pesquisas em três pilares: excelência científica, liderança industrial e desafios societais. $O$ financiamento é em cerca de 80 bilhões de euros disponíveis ao longo de sete anos (2014-2020).

Dentre suas características a Horizonte 2020 determina que:

\begin{abstract}
Para todos os projetos estabelece uma obrigação geral de disseminação em acesso aberto dos resultados, indicando explicitamente que cada beneficiário deve depositar uma cópia de todas as publicações científicas com revisão por pares que sejam respeitantes aos resultados do projeto num repositório e assegurar o acesso logo que possível e no limite de até seis ou doze (para as ciências sociais e humanidades) meses após a publicação.
\end{abstract}

Sendo assim, todos os dados científicos gerados pelas pesquisas financiadas pelo Horizonte $2020^{1}$ devem estar disponíveis em acesso aberto, evoluindo o ideal antigo onde os dados ficavam apenas nos centro de pesquisas e laboratórios. Essa iniciativa promove a disseminação de informações e dados científicos que podem contribuir com pesquisas no mundo todo.

\footnotetext{
${ }^{1}$ Horizonte 2020 - Disponível em: <https://ec.europa.eu/programmes/horizon2020/em>
} 
A fim de atender os requisitos da política Open Acess para o Horizonte 2020, criam-se dois modelos de Infraestrutura de Acesso Aberto para a Investigação na Europa - OpenAIRE e OpenAIREplus, que referem-se a um portal com conjuntos de serviços e informação que buscam contribuir com os pesquisadores para atender aos requisitos impostos pelas políticas de Acesso Aberto.

Dentre os serviços disponibilizados, um dos mais relevantes a serem destacados é o Repositório Zenodo, um ambiente onde, caso o pesquisador não encontre um repositório apropriado para depositar seu conjunto de dados de pesquisa, o portal oferece esse espaço. O Zenodo busca receber dados de pesquisa independente de seu formato, tamanho ou campo da ciência, sejam elas financiadas pelo programa do Horizonte 2020 ou não. É uma iniciativa de colaboração e disseminação de dados científicos de pesquisas que podem contribuir para com outras pesquisas em âmbito mundial.

Segundo Kuramoto (2006), o Brasil encontrava-se nesse mesmo ano em quarto lugar no ranking de países com mais Repositórios Digitais de acesso aberto. Podemos relacionar esse posicionamento no ranking devido ao projeto realizado pelo Instituto Brasileiro de Informação em Ciência e Tecnologia (IBICT), que recebe o nome de "Manifestação Brasileira de Apoio ao Acesso Livre à Informação Científica”, vinculado ao Projeto de lei 1.120/2007 que determina a elaboração de RDs para instituições de ensino e pesquisa que possam "[...] promover o acesso livre à informação científica através da proposta de criação de repositórios digitais por parte das instituições de ensino superior e no depósito de artigos produzidos pela comunidade acadêmica nesses ambientes informacionais." (VIDOTTI; RIBEIRO, 2009, p.107).

Dando seguimento a ideia de acesso aberto, um dos softwares mais utilizados para elaboração dos Repositórios Digitais é o DSpace; além desse ainda existem algumas plataformas gratuitas e de acesso aberto que podem ser utilizadas para a elaboração dos repositórios, como Fedora e Eprints.

Sobre o software livre Dspace:

a) ser um software livre, b) sua arquitetura de software é simples e eficiente, c) uso de tecnologia de ponta, d) direcionado para o acesso aberto, e e) intencionalmente implementado para servir de repositório institucional. No Dspace os dados estão organizados de forma a refletir a estrutura da instituição e se organizam em coleções. (VIANA; MÁRDERO ARELLANO; SHINTAKU, 2005, p. 9) 
O software tornou-se referência por ser uma aplicação de fácil gerenciamento e construção de ambientes informacionais colaborativos, atende bem o processo de customização para o público de cada instituição, além da usabilidade, ou seja, destaca-se por contribuir com o objetivo principal dos Repositórios Digitais que é de disseminar informações geradas nas organizações.

Repositórios Digitais podem ser implantados conforme as necessidades de cada instituição, a fim de atingir da melhor maneira possível seu público-alvo. Contextualizamos três categorias que, apesar de apresentarem estruturas parecidas podem exibir características diferentes. São elas:

- Repositórios Institucionais: "lidam com a produção científica de uma determinada instituição." (LEITE et al., 2012, p.7) - Ex: Repositório Institucional Unesp: http://repositorio.unesp.br/.

- Repositórios Temáticos: "lidam com a produção científica de uma determinada instituição. Tratam, portanto, da produção intelectual de áreas do conhecimento em particular." (LEITE et al., 2012, p.7) - Ex: Repositório Universidade do Porto: https://repositorio-tematico.up.pt/?locale=pt.

- Repositórios de Dados: "entre outros fins, validam resultados de pesquisa, sendo assim, devem ser vinculados de alguma forma às publicações científicas onde mostra para que fossem utilizados esses resultados (dados)". (PÉREZ; MORENO, 2013, p. 261 tradução nossa). Esses repositórios podem ou não ter vínculos aos repositórios institucionais. Ex: Repositório de Acesso Aberto de Portugal http://dados.rcaap.pt/.

As Tecnologias de Informação e Comunicação (TIC), elementos básicos da Arquitetura da Informação - como sistemas de organização, representação, rotulagem e busca -, atributos da Encontrabilidade da Informação, conceitos e tecnologias da Web Semântica, são utilizados para que o funcionamento do sistema informacional atenda todo e qualquer tipo de usuário, fazendo desse ambiente um espaço digital navegável e satisfatório que contribui para o encontro e recuperação das informações de maneira eficiente e eficaz. Além das políticas de funcionamento para padronização e normalização do $\mathrm{RD}$, que se ajusta de acordo com as características dos Repositórios Digitais, que são política de conteúdo, política de preservação, política de metadados, política de submissão, política de autoarquivamento e política de acesso. 
Assim, a Curadoria Digital pode e deve estar presente trabalhando em conjunto a essa políticas dos repositórios digitais, direcionando e validando cada procedimento, principalmente em conjunto com o modelo de ciclo de vida que "[...] permite uma visão coletiva sobre o conjunto de funções necessárias à curadoria e à preservação de dados de pesquisa. Além de definir papeis, responsabilidades e conceitos, ele explicita a infraestrutura de padronização e as tecnologias que devem ser implementadas" (SAYÃO; SALES, 2012, p.187)

Destacamos assim a importância da utilização dos conceitos da Curadoria Digital e do Modelo de Ciclo de Vida dentro de um Repositório Digital, contribuindo para melhorias na qualidade de acesso aos dados científicos, além do aos objetos digitais, assim, "[...] a curadoria contribui para assegurar aos dados de pesquisa validade como registro arquivístico, significando que eles podem ser usados no futuro como evidência legal" (SALES; SAYÃO, 2012, p.126). Esse termo assegura confiabilidade ao ambiente, aos dados científicos e aos objetos digitais.

\subsection{METODOLOGIA}

A metodologia de pesquisa caracteriza-se como exploratória e bibliográfica, possuindo uma abordagem qualitativa, por meio do método de análise de conteúdo. A pesquisa bibliográfica foi realizada em bases de dados nacionais e internacionais, a partir de temas relacionados à: Ciência da Informação, Tecnologia de Informação e Comunicação, Curadoria Digital, Repositório Digital e Preservação Digital.

\section{RESULTADOS PARCIAIS}

Dentro do Curation Lifecycle Mode (CLM) podemos destacar pontos chaves determinantes para que a Curadoria Digital aconteça dentro de um Repositório Digital. O ciclo de vida acontece a partir desses pontos chaves, determinando em cada fase atributos que contribuem na tarefa geral.

Partindo do elemento principal localizado no centro do núcleo do modelo de Curadoria Digital (figura 1) que são os dados, objetos digitais ou banco de dados, as ações determinantes são:

- Ações Completas: ações para todo o ciclo de vida do dado científico, ou seja, dada a criação dos objetos digitais, as ações são pré-definidas para toda a sua existência (De: dado, objetos digitais e bases de dado até curar e preservar); 
- Ações Sequenciais: ações frequentes realizadas aos dados que remetem ao recebimento, avaliação, representação, uso e preservação (De: criação e/ou recebimento até transformação);

- Ações Ocasionais: ações necessárias, porém utilizadas com menos frequência, como a migração de dados (Reavaliar - de: Ações de preservação para avaliação e seleção/Migrar - de: ações de preservação para transformação).

Relatamos anteriormente nesse texto que os Repositórios Digitais estão diretamente associados ao Movimento de Acesso Aberto, dentro desse contexto utiliza-se de softwares livres disponibilizado de modo aberto - em grande parte o Dspace.

O software DSpace utiliza o padrão Dublin Core, OAl-PMH (Open Archive Initiative - Protocol for Metadata Havesting). Nesse padrão são apresentados dois níveis de descrição dos metadados, simples e qualificados. Além disso, o OA/-PMH permite a interoperabilidade, facilitando $o$ processo de disseminação e compartilhamento de dados.

A linguagem de descrição e representação de metadados utilizados pelo Dublin Core são XML (eXtensible Markup Language) ou RDF (Resource Description Framework). A representação da informação realizada a partir de um software de fácil gerenciamento e bem estruturado é essencial, contribuindo efetivamente com as funções da curadoria digital e preservação. São as descrições por meio de metadados que representam e agregam semântica aos dados e objetos digitais inseridos nos repositórios, podendo ser vocabulários controlados, tesauros e metadados para melhor padronização. Segundo Clair (2011), ainda existe uma lacuna nessa área - a falta de um vocabulário de dados para expressar as informações de um objeto para sua preservação. Um possível avanço seria a criação de uma ontologia OWL como, por exemplo, o PREMIS.

O Curation Lifecycle Model (CLM) trata de um modelo completo que pode auxiliar os gestores dos Repositórios Digitais para que se tenha uma visão ampla das funções da curadoria. Além de facilitar a visualização, o CLM facilita o processo de implementação das funções de curadoria, o que contribui para que a equipe possa seguir as etapas garantindo que nenhum processo seja esquecido e que o ciclo aconteça por completo. Principalmente em relação às ações ocasionais, é importante que toda a equipe gestora do repositório esteja atenta aos formatos dos dados inseridos, a preocupação com obsolescência ou atualizações de softwares e 
etc, buscando sempre acompanhar as Tecnologias de Informação e Comunicação (TIC) e garantindo sempre uso e reuso das informações.

\section{CONSIDERAÇÕES PARCIAIS/FINAIS}

Vivemos atualmente em um cenário onde a disseminação de informação aumenta exponencialmente exigindo da Ciência da Informação a necessidade de ambientes informacionais digitais estruturados, como os Repositórios Digitais.

Segundo o website da DCC, só no Reino Unido mais de 3 bilhões do dinheiro público são investidos em pesquisa e muitas vezes não se tem acesso a esses resultados. Portanto, se faz necessária a conscientização de que é preciso um compartilhamento de dados de maneira aberta com qualidade. Para isso deve-se por em prática os conceitos da curadoria, além de cuidadores digitais trabalhando na gestão do ciclo de vida desses dados. Uma vez que se torne cultural o processo de preservação e compartilhamento de dados científicos abertamente, haverá a compreensão de quão grande será o impacto dentro da comunidade científica gerando confiabilidade para as instituições de financiamento para que invistam cada vez mais em pesquisas e, assim, garantindo a salvaguarda adequada para uso futuro.

Podemos concluir que uma das principais soluções para que a preservação digital aconteça está ligada às funções apresentadas no Modelo de Ciclo de Vida da DCC, onde são encontrados os processos a serem realizados.

Nesse contexto, um dos maiores problemas está ligado a Representação da Informação, que influencia na Recuperação da Informação pelos usuários, dificultando o uso e reuso das informações no presente e no futuro. Ainda se faz necessário aprofundamento dentro do tema da Curadoria Digital e no seu modelo, principalmente quando se trata de repositórios digitais, que hoje trabalham apenas com objetos digitais. As propostas para repositórios que armazenem dados são novas no cenário da Ciência da Informação, assim como o tema Curadoria. Entendemos que o modelo tem como foco dados, objetos digitais e bases de dados, entretanto, o que se encontra na literatura na maioria das vezes é a aplicação em uma curadoria voltada aos dados científicos.

Concluímos assim, que a Curadoria Digital dentro do cenário da Ciência da Informação é ainda um assunto novo e em expansão, que necessita das realizações 
de estudos para aprofundamento no tema. Entretanto, podemos notar claramente que existem grandes possibilidades de contribuição em Repositórios Digitais por meio do uso do modelo do CLM, que oferece um planejamento completo para que se possa garantir qualidade na organização, estruturação, representação, recuperação e preservação dos dados e objetos digitais inseridos nos RDs. Principalmente de instituições de ensino e pesquisa que geram quantidades grandiosas de pesquisa de extrema relevância à sociedade e comunidade científica, e que se preocupam além da disseminação de suas produções científicas, em garantirem sua memória institucional.

\section{REFERÊNCIAS}

ABBOTT, D. What is digital curation? Digital Curation Center, 2008.Disponível em: <https://www.era.lib.ed.ac.uk/bitstream/handle/1842/3362/Abbott\%20What\%20is\%20 digital\%20curation_\%20_\%20Digital\%20Curation\%20Centre.pdf?sequence=2>. Acesso: 27 jul. 2016.

ATKINSON, M. et al. The Digital Curation Centre: A vision for digital curation. Data Interoperability-Challenges and Technologies, v. 26, p. 2007, 2005. Disponível em: <file:///E:/Resumos\%20e\%20prints/l\%20FORUM\%20DE\%20REP\%20DIGITAIS \%20-\%20RN/151-682-1-PB.pdf>. Acesso em: 28 jul. 2016.

BUDAPESTE open access iniciative. 2001. Disponível em: <http://www.budapest openaccessinitiative.org/>. Acesso em: 13 jul. 2016.

CLAIR, K. Metadata for a micro-services-based digital curation system.

In: International Conference on Dublin Core and Metadata Applications. 2011. p. 5862. Disponível em: <http://dcpapers.dublincore.org/index.php/pubs/article/view/ 3631>. Acesso em: 2 ago. 2016.

HERNÁNDEZ-PÉREZ, A; GARCÍA-MORENO, M. A. Datos abiertos y repositorios de datos: nuevo reto para los bibliotecarios. El profesional de la información. Barcelona, v. 22, n. 3, p. 259-263, maio/junho. 2013. Disponível em: <http://orff. uc3m.es/handle/10016/17209>. Acesso em: 28 jul. 2016.

KURAMOTO, H. Informação científica: proposta de um novo modelo para o Brasil. Ciência da Informação. Brasília, v. 35, n. 2, p. 91-102, maio/ago. 2006. Disponível em: <http://www.scielo.br/pdf/ci/v35n2/a10v35n2.pdf>. Acesso em: 20 jul. 2016.

LEITE, F. et al. Boas práticas para a construção de repositórios institucionais da produção científica. Brasília: Ibict, 2012, 34p. Disponível em: <http://livroaberto.ibict.br/handle/1/703 >. Acesso em: 13 jul. 2016. 
PRÍNCIPE, P; RODRIGUES, E. Infraestrutura OpenAIRE: serviço para implementação do Acesso Aberto no Horizonte 2020. Cadernos BAD, n. 2, p. 67-76, 2014. Disponível em: <http://www.bad.pt/publicacoes/index.php/cadernos/article/ view/1181>. Acesso em: 28 jul. 2016.

RIBEIRO, O. B; VIDOTTI, S.A.B.G. Otimização do acesso à informação científica: discussão sobre a aplicação de elementos da arquitetura da informação em repositórios digitais. BIBLOS: Revista do Instituto de Ciências Humanas e da Informação, v. 23, n. 2, p. 105-116, 2009.

RODRIGUES, E. O acesso aberto (na UMinho e no mundo): onde estamos e por onde vamos?. Revista Eletrônica de Comunicação, Informação \& Inovação em Saúde, v. 8, n. 2, 2014.

SANTAREM SEGUNDO, J. E. Representação iterativa: um modelo para repositórios digitais. 2010. 224 f. Tese (Doutorado) - Universidade Estadual Paulista, Faculdade de Filosofia e Ciências, 2010. Disponível em: <http://hdl.handle. net/ 11449/103346>. Acesso em: 26 jul. 2016.

SANTOS, T. N. C. Curadoria digital: o conceito no período de 2000 a 2013. 2014. 165 f. Dissertação (Mestrado em Ciência da Informação) - Universidade de Brasília, Brasília, 2014. Disponível em: <http://repositorio.unb.br/handle/10482/17324>. Acesso: 27 jul. 2016.

SAYÃO, L. F; SALES, L. F. Curadoria digital: um novo patamar para preservação de dados digitais de pesquisa. Inf. \& Soc.: Estudos, João Pessoa, v. 22, n.3. p.179-191, set./dez. 2012. Disponível em: <http://search.proquest.com/openview/82ecc 12d22135fd5a2510ac8fdeec623/1 ?pq-origsite=gscholar>. Acesso em: 25 jul. 2016.

O impacto da curadoria digital dos dados de pesquisa na comunicação científica. Enc. Bibli: R.Eletr. Bib. Ci. Inf., v.17, n. esp. 2, p.118-135, 2012. III SBCC. Disponível em: <http://carpedien.ien.gov.br:8080/bitstream/ien/667/1/27417-90333-1PB.pdf>. Acesso em: 25 jun. 2016.

Dados de pesquisa: contribuição para o estabelecimento de um modelo de curadoria digital para o país. Tendências da Pesquisa Brasileira em Ciência da Informação, v. 6, n. 1, 2013. Disponível em: <http://inseer.ibict.br/ancib/index.php/ tpbci/article/viewArticle/102>. Acesso em: 25 jul. 2016.

SIEBRA, S. A et al. Curadoria digital: além da questão da preservação digital. In: ENCONTRO NACIONAL DE PESQUISA EM CIÊNCIA DA INFORMAÇÃO (ENANCIB 2013), 14., 2013, Florianópolis. Anais... Florianópolis: UFSC, 2013.

TERRA, C. F. Usuário Mídia: o curador das mídias sociais? In: SAAD. E. C. Curadoria digital e o sub campo da comunicação. São Paulo: Eca - Usp, 2012. Disponível em: <https://issuu.com/grupoecausp.com/docs/ebook_curadoria_Digital _usp>. Acesso em: 25 maio 2016.

VIANA, C. L. M; M, MÁRDERO, A; SHINTAKU, M. Repositórios institucionais em ciência e tecnologia: uma experiência de customização do DSpace. In: Simpósio 
Internacional de Bibliotecas Digitais. 3., São Paulo, 2005. Anais... São Paulo, USP; SIBI, 2005. p. 1-27. 